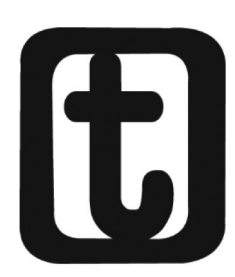

\title{
NO FIO DA MEADA: \\ UM ESTUDO ACERCA DA PRECARIZAÇÃO DO TRABALHO NA INDÚSTRIA TÊXTIL
}

\author{
THE TRAIN OF THOUGHT: \\ A STUDY ABOUT WORK IN PRECARIOUSNESS TEXTILE INDUSTRY
}

\author{
Hiago Trindade de Lira Silva
}

\section{RESUMO}

Este texto pretende fornecer uma aproximação das contradições que marcam a realidade do operariado têxtil inserido na indústria potiguar "Casa de Costura”. Para tanto, além de proceder à revisão da literatura, estamos ancorados nos dados produzidos mediante realização de entrevistas semiestruturadas com o operariado fabril. O resultado de nossas incursões investigativas nos permite compreender as alterações processadas no âmbito da indústria estudada e elucidar como diferentes mecanismos de organização do espaço produtivo persistem no desenvolvimento das atividades, conformando um arranjo particular na gestão da força de trabalho.

Palavras-Chave: Precarização do trabalho. Indústria Têxtil. Gestão da Força de Trabalho.

\section{ABSTRACT}

This text intends to provide an approximation of the contradictions that mark the reality of the textile laborer inserted in the potiguar industry "Casa de Costura". Therefore, in addition to proceeding literature review, we are anchored in the data produced by conducting semi-structured interviews with the factory workers. The result of our investigative incursions allows us to understand the alterations processed in the scope of the studied industry and to elucidate how different mechanisms of organization of the productive

1 Doutorando em Serviço Social pela Universidade Federal do Rio de Janeiro. 


\section{temporollis}

space persist in the development of the activities, conforming a particular arrangement in the management of the work force.

Keywords: Precarious Work. Textile Industry. Workforce Management.

Submissão - 21/08/2016

Aceite - 13/01/2017

\section{Introdução}

Todo capitalista que se preze sempre se esforça em fazer transparecer, aos olhos de todos, uma imagem positiva de suas fábricas. Existem, aos montes, discursos e reportagens que enfatizam a responsabilidade social das empresas ou, ainda, matérias que realçam como os trabalhadores, gentilmente chamados de "colaboradores", são felizes em fazer parte dessa verdadeira "família". Todavia, o texto que ora redigimos se constrói com uma intenção contrária a esta: pretende fornecer uma aproximação das contradições que marcam a realidade daqueles que, vivendo no fio da meada, necessitam se submeter aos ditames do capital. Mais precisamente, iremos nos debruçar sobre as condições de trabalho do operariado têxtil da indústria potiguar "Casa de Costura". 2

Como sabemos, na contemporaneidade, diante do contexto de crise do capital que se aprofunda cada dia mais, inúmeras estratégias são materializadas pelos setores burgueses tendo por objetivo primeiro criar as condições necessárias para a (re)produção do sistema de metabolismos de segunda ordem, nos termos de Mészáros (2009). Dentre essas estratégias, presenciamos o desenvolvimento de um intenso e profundo processo de reestruturação produtiva no âmbito fabril-industrial que modifica fortemente a maneira de ser, existir e se organizar da classe trabalhadora.

Tal processo ganha contornos e traços particulares a depender de cada região. Assim, a partir das entrevistas realizadas com homens e mulheres ${ }^{3}$ que estiveram ou que ainda estão trabalhando nos di-

2 Casa de Costura é o nome fictício dado à indústria investigada. Trata-se de uma fábrica alocada no estado do Rio Grande do Norte. Ela galga uma posição de destaque não apenas na região Nordeste, mas em toda a América Latina, posto ter se colocado nesse cenário como uma das principais indústrias do ramo, tanto pelo volume de produção, quanto pela quantidade de trabalhadores que a dinamizam.

3 Os nomes dos entrevistados, aqui, foram substituídos pelos seguintes codinomes: Annie Rosen, Rosey Safran, Jacob Klein, Bennie Sklawer, Sam Lehrer, Ida Jacobowski, 


\section{tempordilis}

versos ramos/funções na Casa de Costura, podemos identificar como se materializam essas investidas na realidade específica da indústria têxtil norte-rio-grandense. Nosso esforço em desvelar a realidade se pauta na análise crítica das condições e relações de trabalho lá estabelecidas, bem como, no levantamento das modificações operadas no que tange à gestão da força de trabalho e as estratégias e direcionamentos implementados pelos capitalistas na constante e ininterrupta tentativa de potencializar o desenvolvimento do processo produtivo para obter níveis cada vez maiores de mais-valia. Percorremos, assim, os setores que compõem a Casa de Costura, da malharia ao acabamento, e criamos as vias necessárias para liquidar as barreiras que procuram esconder toda a sorte de exploração, como também para avançar no entendimento da lógica de funcionamento e das contradições que a fábrica carrega.

Assim, é chegada a hora de ultrapassar os muros cinzentos, de pôr a nu tudo o que aquela fábrica revela e esconde, em sua dialética cotidiana do trabalho; é hora de deixar ecoar os gritos, as dores e sofrimentos de tantas mulheres e homens que lá encontram-se emaranhados em fios perversos, aprisionados como escravos a produzir incessantemente! É hora de tirar a máscara do burguês, para que nós, enquanto trabalhadores, possamos tomar consciência do nosso verdadeiro inimigo. É, em síntese, hora de abrir os olhos para tomar ciência da necessidade de quebrar os grilhões que ligam o operariado a uma vida sem sentido. Sigamos, então, trilhando os caminhos da fábrica...

\section{Percorrendo a fábrica: trabalhadores emaranhados pelos fios do capital}

A entrada na fábrica é impactante desde os primeiros momentos: milhares de aparelhos produzem um som insuportável que, certa-

Luiza Brancaccio e Zuzu Angel. Com exceção dos dois últimos nomes, todas as outras pessoas eram operários da indústria têxtil Triangle Shirtwaist, localizada em Nova lorque, onde eram, tal como os trabalhadores da Casa de Costura, submetidos a extensas e duras jornadas de trabalho. Em 1911, no início do século XX, sucedeuse naquela fábrica um terrível acontecimento: um incêndio alastrou-se pelo prédio, levando cruelmente à morte cerca de 146 jovens costureiras. O episódio marcou fortemente as pessoas à época e ainda nos dias atuais é aludido; inclusive, serviu de motivação para a eclosão de protestos e para a promulgação do Dia Internacional da Mulher, em 8 de Março. (GONZÁLEZ, 2010). 


\title{
temporollis
}

mente, fica martelando na cabeça dos trabalhadores durante o período de sua jornada de trabalho. Do ponto de vista objetivo não há conforto. O teto é constituído de uma espécie de brasilit, um material que absorve e irradia bastante calor. Além disso, as inúmeras lâmpadas acesas também contribuem para aumentar, ainda mais, este efeito. Ora, numa localidade marcada por elevadas temperaturas durante a maior parte do ano, portanto, este calor se eleva consideravelmente, afetando todos os que estão no ambiente. Nesse sentido, é emblemático o relato de uma trabalhadora:

\begin{abstract}
A questão do calor, também... olhe... questões ambientais, assim... [...] o barulho! O calor... ei, época de calor, gente é de morrer! Desmaia gente! Desmaia gente, assim, desmaia! É... [...] tem pessoas lá que anda com uma toalhinha... aí molha a toalhinha e bota aqui no pescoço pra poder trabalhar... pra vê se dá um alívio da quentura, [...] porque é muito quente! (ANNIE ROSEN).
\end{abstract}

No que tange à questão do conforto, observamos ainda que o espaço ocupado pelos trabalhadores é bastante exíguo. Cada um deles tem uma pequena área, constituída pura e simplesmente do espaço suficiente para desempenhar suas atividades. Vivem, assim, encurralados pelas máquinas que os cercam por todas as direções. Não podem "sair da linha", ou seja, devem andar conforme o embalo da empresa. Os inúmeros fios também fazem parte do cenário da indústria, dando uma impressão de um emaranhado constante.

A descrição feita por Annie Rosen é ilustrativa dessa realidade. Em sua fala, ela relata as impressões que teve ao chegar à Casa de Costura, em seu primeiro dia de trabalho. Vejamos:

É como se fosse um depósito de pessoas, eu tô sendo
sincera com você, eu tô dizendo porque eu vivenciei isso
[...] Quando eu cheguei na [Casa de Costura], quando
eu vi aquilo, assim, a sensação que você tem... porque
é muito fio sabe? [...] quando você chega... [...] nossa
no primeiro dia ali foi... eu já tinha trabalhado noutras,
mas num era daquela maneira. [...] É diferente, eu acho
que quanto mais se moderniza, mais as coisas ficam [pi-
ores]... gente... quando eu cheguei lá [...], aqueles fios
todos assim, né? (ANNIE ROSEN).

Na fala de nossa entrevistada, identificamos uma espécie de estranhamento em face à situação em que a empresa se encontra mesmo diante da "modernização". Percebemos que, para ela, tal mo- 
dernização deveria expressar uma melhoria nas condições e relações de trabalho no universo da empresa. Infelizmente, a realidade não é esta. Nos marcos de aprofundamento das crises do capital, modernizar significa, tão somente, encontrar formas de aumentar as taxas de lucratividade da empresa, o que têm correspondido, sempre, a emersão e/ou aprofundamento de formas de trabalho cada vez mais precarizadas, sobremaneira com as determinações da chamada acumulação flexível, como aponta Harvey (1992).

Interessante observar também algumas nomenclaturas utilizadas pelas operárias para descrever o ambiente de trabalho. Annie fala em um "depósito de pessoas", o que nos soa como uma tentativa de demonstrar a perda da humanidade dos sujeitos naquele ambiente, já que, como sabemos, um depósito é um espaço destinado, em geral, a acomodar mercadorias ou utensílios velhos/com pouca utilidade. Rosey Safran, por sua vez, faz uma analogia ainda mais forte para qualificar o espaço em que desenvolvia suas atividades. Para ela, trata-se de um "matador" - e ela nos explica o porquê disto:

\footnotetext{
Olhe, era bem organizado lá, os setores... o matador era bem organizado... [O matador?!] É, por que ali, meu filho, quem num sai dali... quase todo mundo que sai dali, sai com problema... problema de estresse, sistema nervoso [...]. (ROSEY SAFRAN).
}

A fala acima transcrita é impactante, mas demonstra as impressões, apoiadas na própria vivência de uma trabalhadora que, objetiva e subjetivamente, sentiu-se afetada pela dinâmica das relações de trabalho lá estabelecidas. Mais cruel ainda, especificamente no caso de Rosey, é constatar que, mesmo fazendo esta análise de seu ambiente de trabalho, ou seja, mesmo reconhecendo que ele a prejudicava acentuadamente, ela não tinha para onde ir. Necessitou, assim, se submeter ao "matador" e só saiu de lá porque a demitiram, alegando que ela não conseguia atingir as metas de produtividade estabelecidas.

A Casa de Costura não se ocupa apenas da costura das peças de roupa. Ela também produz parte dos tecidos requisitados pela indústria, mais precisamente aqueles utilizados na confecção das vestimentas.

No setor responsável pela produção das malhas, os operários trabalham com duas máquinas, quais sejam, Orizio e Fukuhara, que 


\section{temporollis}

produzem tipos diferentes de malha: a primeira, italiana, produz à meia-malha ou malha crua e a segunda, japonesa, gera o piquê-duplo (usado nas camisas de tipo polo). Assim, no interior da indústria, mediante exploração da força de trabalho humano e com a utilização dessas máquinas e equipamentos tecnologicamente avançados, as fibras geram os fios e estes, por sua vez, dão origem aos tecidos. Esse processo de transformação do fio em tecido ocorre no setor de maIharia, sobre o qual discorreremos algumas palavras.

No setor supramencionado, perduram algumas questões presentes em outros departamentos da indústria, mas, obviamente, também existem algumas particularidades. Há nele, por exemplo, a exigência das metas de produtividade. Contudo, neste caso, elas não se realizam exclusivamente pela disposição ou destreza dos trabalhadores e, sim, em função do desempenho de algumas máquinas. As "máquinas ruins" eram, no dizer de Jacob Klein, o motivo de determinadas pessoas não alcançarem as metas instituídas. Este mesmo entrevistado afirma que o trabalho era bom por haver uma "estabilidade", mas, ao mesmo tempo, nos relata o grau de exploração que passavam até pouco tempo antes:

[Você assumia] mais de uma função, não existia uma disciplina. Por exemplo, eu era mecânico, mas eu tinha que varrer, tinha que acompanhar a produção, eu tinha que encaixar fio, tinha que abastecer máquina, tudo função diferente da de mecânica. (JACOB KLEIN).

De acordo com o operário, esta era a situação vivenciada na empresa até 2010, momento no qual houve modificações responsáveis por alterar esta realidade. A partir deste ano, tudo está sendo definido pela meritocracia. Traduzindo: se você estudar e se capacitar, poderá galgar um cargo melhor na indústria. Mas, ao mesmo tempo, não basta ser um profissional capacitado e não estar em sintonia com o espírito da empresa, ou seja, com o conjunto de valores, princípios e direcionamentos que legitimam sua existência. Nesse sentido, é preciso se enquadrar no perfil de funcionário requisitado. É preciso andar nos trilhos. É preciso, em resumo, "trabalhar direito", pois, como afirma Jacob:

Você trabalhando direito você trabalhava 20 anos, como eu passei 27, né? (JACOB KLEIN).

Trabalhar direito é, nessa ótica, o mesmo que se submeter às 


\section{tempordis}

condições e relações de trabalho exigidas pela empresa sem desviar a atenção para perceber erros e incongruências, ou ainda para apontar dificuldades no serviço realizado. Significa, em síntese, aceitar passivamente as ordens e executá-las sempre da melhor forma possível e com o máximo de dedicação e atenção.

Parece-nos ser uma marca evidente da Casa de Costura, tomada em sua totalidade, querer utilizar, o máximo possível, ou seja, de forma intensiva e, em alguns casos, extensiva, a força de trabalho dos que estão à sua disposição. Esse é o fio condutor que interliga todos os trabalhadores que lá se encontram, desde a costura, passando pelo acabamento, tinturaria e malharia. Serem fortemente explorados é a marca que carregam estes trabalhadores e trabalhadoras nesse novo (e precário) mundo do trabalho no Brasil, para fazer alusão à expressão cunhada por Alves (2005).

De acordo com nossas entrevistas, notamos que, em virtude das possibilidades de compra de tecidos oriundos da china, compra esta que, certamente, apresenta mais vantagens financeiras para o capitalista, a máquina Orizio vem cumprindo um papel secundário no âmbito da produção dos tecidos. Vejamos:

[...] quando o mercado da China entrou aí eles compram da China a malha [...] com a malha da China num precisa produzir, eles produzem só pra fazer a média, tá entendendo? [...] a China tá tomando conta. (JACOB KLEIN).

Em tempos de mundialização do capital, Chesnais (1996), as relações de importação e exportação entre diferentes países se acentuam e mesmo se acirram em meio à disputa por mercados, como vem acontecendo no caso do ramo têxtil, em que os países asiáticos, em especial a China e a Índia, têm apresentado uma posição de destaque no cenário internacional. Nesse caso, é preciso não perder de vista que o tecido importado da China é mais acessível do ponto de vista econômico, na exata medida em que, naquele país, além da produção de tecnologias na área, a exploração dos superabundantes trabalhadores é intensa e a remuneração que lhes é atribuída é baixíssima. Desse modo, para o capitalista, o valor dos tecidos adquiridos pode até ser reduzido, mas para o conjunto de homens e mulheres que vendem sua força de trabalho, o preço pago é altíssimo: viver a vida no embalo da exploração e precarização do trabalho.

Os tecidos que ainda são produzidos na Casa de Costura, saem 


\section{temporollis}

em seu estado "cru", como é comumente caracterizado. Para ganhar cores, eles passam pelo setor de tinturaria. Tratam-se, assim, de departamentos específicos da indústria, com objetivos direcionados para cada uma destas funções.

Neste setor, que compreende basicamente a parte de serigrafia e tingimento dos tecidos em geral, dois momentos históricos se destacam: uma fase manual, com vigor até 2008/2009, e outra marcada pela incorporação de uma máquina vinda de Portugal, a Sroque, entre os anos de 2009/2010 - mesma ocasião em que também vieram as máquinas para o setor de malharia. No período de produção manual, prevaleciam características mais ligadas ao modelo fordista4: as estampas eram feitas uma a uma, com tela e rodo, e as metas de produtividade eram estabelecidas de acordo com a quantidade de cores presentes nos desenhos estampados, tomando-se por base a atividade de serigrafia. Com a incorporação das máquinas, várias peças passaram a ser estampadas ao mesmo tempo. As metas continuaram existindo, mas, agora por turno de trabalho. Ao todo, são três turnos que se alternam nas $24 \mathrm{~h}$ do dia. O número de operários na função foi drasticamente reduzido.

De acordo com nosso entrevistado, no período manual a utilização de um avental de couro pesado, em virtude de as mesas de trabalho serem térmicas, dificultava a agilidade na produção, mas, ainda assim, as metas conseguiam ser atendidas. Com a inserção das máquinas, ainda de acordo com ele, também não houve maiores dificuldades para atingir a qualidade e os níveis de produtividade requeridos.

Diferentemente de outros setores, em que predomina o exercício de múltiplas funções pelos trabalhadores a partir dos princípios de polivalência que guiam a cartilha de flexibilização do trabalho (HARVEY, 1992; PINTO, 2010), na parte da tinturaria cada operário desempenha apenas uma tarefa específica, como nos esclarece um trabalhador:

[...] lá todo mundo tem um objetivo, um canto de ficar. Tem tudo bem especificadozinho, quem fica nas pastas, quem tomava conta das tintas, quem tomava de conta da parte de roupa, tudo era separado, na parte de rev-

4 Para Ricardo Antunes (2013), o fordismo tinha como principais características: produção em massa, homogeneizada e verticalizada, com uma linha rígida de produção e trabalho fragmentado. 


\section{temporolis}

elação já era outro... lá é bem organizado, lá... (BENNIE SKLAWER).

Mas, nesse ambiente, algo nos chamou especial atenção: o fato de este ser um setor que lida com substâncias químicas/tóxicas e de os operários que nele ingressam não passarem por nenhum tipo de treinamento para manusear os itens e desenvolver o trabalho com maior segurança. Aliás, no âmbito da Casa de Costura, o treinamento, no momento da inserção, destina-se apenas para as costureiras. A entrada nos demais setores, sobremaneira daqueles que carregam o status de "mais pesados" e que são ocupados fundamentalmente por pessoas do sexo masculino, ocorre sem que a empresa ofereça capacitação adequada.

Nesses tipos de função, em específico, a habilitação dos funcionários para o exercício do trabalho dá-se na dinâmica que embala o cotidiano da produção, ou como nos relatou Bennie Sklawer, "na base de peão". O ambiente e os artefatos presentes no dia a dia dos trabalhadores da tinturaria foi-nos apresentado por nosso entrevistado:

[...] você trabalhava com produtos químicos demais... solvente, nossa [...] aqueles biodiesel, é muita tinta, muito tipo de tinta misturado, fumaça.... muita coisa ali dentro! (BENNIE SKLAWER).

Certamente, este é um caso em que as condições de trabalho materializadas no contrato de trabalho e/ou em outros documentos que tratam do vínculo estabelecido pelo trabalhador, diferem daquelas que, depois de inseridos no ambiente de trabalho insalubre, degradante e permeado por riscos, estes sujeitos encontram (SILVA; GUERRA, 2017). Além disso, aprender a realizar as funções exigidas na "na base de peão" representa uma série de riscos e consequências para os trabalhadores. ${ }^{5} \mathrm{Na}$ entrevista que nos forneceu, por exemplo, Bennie relata ter se aproximado, certa vez, de um solvente; e, por não conhecer o produto ou por não saber a maneira correta de manuseá-lo, acabou sofrendo um acidente, como relatado abaixo:

5 Como alertou Marx (1989): “O capital não tem [...] a menor consideração com a saúde e com a vida do trabalhador, a não ser quando a sociedade o compele a respeitá-las. À queixa sobre a degradação física e mental, morte prematura, suplício do trabalho levado até a completa exaustão responde: por que nos atormentaremos com esses sofrimentos se eles aumentam nossos lucros?" 


\title{
temporollis
}

\begin{abstract}
Ah, que eu também nunca tinha mexido, né? Foi na parte do solvente, que eu botei as mãos dentro [...], minha mão pipocou todinha. (BENNIE SKLAWER).
\end{abstract}

Felizmente, no caso que envolveu o operário em questão, o acidente não ocasionou maiores consequências, mas poderia ter causado, sem sombra de dúvidas. Os acidentes de trabalho, assim, são constantes. Eles perduraram mesmo na fase de inserção das máquinas. Ora, com as alterações processadas, embora o contato dos trabaIhadores com os produtos químicos tenha diminuído, outras determinações passaram a fazer parte de seu cotidiano de trabalho. Vejamos:

Quando chegou a máquina, diminuiu... continuava mexendo com produtos, mas diminuiu [...] Pronto, diminuiu a parte de química, mas de acidentes, de jeito nenhum. Acidente ali já mudou, já ficou mais perigoso porque [...] lá tinha umas barras [...], já vi gente quebrar pé, se queimar... já vi muita desgraça ali dentro, home! (BENNIE SKLAWER).

Além das dificuldades relacionadas aos acidentes de trabalho, outro quesito foi apontado por nosso entrevistado: a remuneração. Segundo ele, o salário que embolsava não era equivalente à função que exercia na indústria. Ele recebia uma quantidade inferior ao realmente devido. Em verdade, nos marcos da precarização estrutural do trabalho, a dimensão da remuneração se associa às péssimas condições e relações que regem seu emprego tornando o trabalho extremamente degradante (ALVES, 2014). A despeito disso, Bennie conseguiu progredir na empresa, no sentido de ocupar funções mais favoráveis. Mas, mesmo assim, quando encontrou outra oportunidade de trabalho, não hesitou em deixar a fábrica. Hoje, ele continua trabalhando "na profissão que aprendeu na Casa de Costura". Aprendeu, mas a duras penas, diríamos.

Por sua vez, o setor de acabamento é responsável pela execução das últimas atividades necessárias para que as mercadorias possam ser encaminhadas para a venda nas lojas. São elas: pistolar, colocar o preço, engomar e embalar as peças já fabricadas, exatamente nessa ordem. Há um grupo composto por aproximadamente 60 pessoas que é responsável por todas estas tarefas, realizadas já depois de o produto ter passado pelos setores da malharia e tinturaria. A equipe é mista, composta por homens e mulheres. Mas, recentemente, as mulheres deixaram de ser direcionadas para a função do engomado, tendo em vista que as mesmas apresentavam diversas dificuldades. 


\section{temporolis}

Vejamos:

A parte do engomado é só homem. Antigamente era homem e mulher, mas começou aparecer, incomodar as mulheres, umas começaram a adoecer por causa do vapor, a temperatura muito quente, aí retiraram as mulheres e deixaram só os homens. (SAM LEHRER).

Ao mesmo tempo, quando esta mudança ocorreu, Sam chama a atenção para o fato de a empresa não ter despedido as mulheres que estavam exercendo aquela função e, sim, ter tentado "encaixá-las" em outras atividades, o que, na verdade, é algo que a Casa de Costura conhece muito bem: flexibilizar! No âmbito do acabamento, a parte do engomado é a pior. Certamente, por isso, quando novos trabalhadores vão se inserir - diga-se, também sem passar por capacitações ou treinamentos - eles devem começar por esta tarefa. Isto nos soa como uma espécie de "teste", pois se o trabalhador consegue resistir àquele posto tão degradante, com certeza não terá dificuldade nos demais.

Ali a gente começa tudo dentro do engomado, pra gente chegar, pra partir, pra colocar preço, pra pistolar, a gente primeiro tem que sair de dentro do engomado, certo? (SAM LEHRER).

Neste setor, as pessoas se organizam em subgrupos para desempenhar cada uma das funções exigidas e fazem um revezamento para que todos possam se apropriar do conhecimento necessário para executar qualquer uma das funções que conformam o espaço. No setor de acabamento também é preciso saber desenvolver várias atividades, é necessário ser polivalente! Nas palavras de um operário:

A gente trabalha em termo de rodízio. Vamos supor assim que, uma semana, o máximo duas semanas, a gente separa um grupo pra colocar preço, noutra semana outra pessoa pra pistolar as peças... (SAM LEHRER).

A produção pode ser mais ou menos demorada a depender do tipo de remessa que lhes chega. No caso, quando as costureiras estão defronte de uma remessa complicada, o tempo necessário para confeccionar as peças é maior. E, se o tempo é maior, a quantidade de utensílios produzidos diariamente também será reduzida.

Essa situação rebate diretamente no setor de embalagem, posto que, para atingirem suas metas de produtividade - a qual, de 


\section{temporollis}

acordo com nosso entrevistado, oscila entre 23.000 e 25.000 peças por dia -, eles dependem das mercadorias que chegam até eles. Nesse sentido, embora não tenha sido uma informação evidente em nossas entrevistas, cremos que esta é mais uma forma de as costureiras se sentirem pressionadas e criarem mecanismos para fazer avançar a produção.

Observamos como esta situação é interessante do ponto de vista da gestão da força de trabalho na indústria têxtil. Aqui, estabelece-se uma relação de estreita dependência entre o amplo setor da costura e o departamento encarregado pelo acabamento, donde este último só consegue levar a cabo suas atividades se, no âmbito do primeiro, tudo fluir bem, pois é de lá que advém o material imprescindível ao trabalho que executam. Destarte, embora na contemporaneidade as formas de organização do trabalho queiram ter a marca da autonomia e autogestão (como acontece com maior facilidade nos setores de malharia e tinturaria, por exemplo), nem tudo pode se resolver no interior das Pequenas Unidades de Produção (PUP) 6 , dos "times", etc. Ainda há, assim, momentos em que a dependência é inevitável. Na situação em apreço, nos vem à memória a lembrança da própria dependência que uns e outros trabalhadores firmavam no marco da esteira fordista. Nos dias que correm, contudo, ela não se estabelece entre sujeitos individuais, mas entre os setores que a compõe.

Em virtude desta situação, Sam Lehrer nos informa que, em alguns momentos, o setor não consegue atingir a produção desejada. Todavia, quando isto acontece, eles já sabem o que fazer:

[...] se hoje a gente num conseguir, amanhã a gente corre atrás pra vê se... repor aquele dia que a gente não conseguiu, e sempre... um dia atrás do outro, correndo atrás pra vê se mantêm a meta pra fazer a embalagem. (SAM LEHRER).

O esforço em correr contra o tempo para atingir as metas dáse, pelo menos, por dois motivos: o primeiro refere-se à pertinência de demonstrar, para a empresa e seus dirigentes, a capacidade produtiva que o grupo possui. Se os operários passam uma boa imagem para seus superiores, poderão ser lembrados no momento de uma promoção. Especialmente tomando-se por base o caso deste trabalhador,

6 Configuram-se como um agrupamento composto por 15 indivíduos que são responsáveis pela realização de determinada tarefa. 
sabemos da importância que é para ele ter um vínculo com carteira assinada. Em sua entrevista, Sam, que ainda é um jovem, nos diz que trabalhou um largo espaço de tempo por contrato. Inicialmente, por que não podiam assinar sua carteira em virtude de não possuir a idade requerida e, depois, porque não encontrava emprego. Nesse sentido, hoje, ele procura zelar o máximo por este trabalho, se empenhando e mobilizando para que tudo saia nos conformes. Já o segundo motivo está associado ao fato de os trabalhadores (não só os da embalagem, mas de toda a empresa) terem participação na produção, ou seja: quanto maior for ela, maior também será seu salário.

Sam quer, também, aproveitar os "bons ventos" que estão soprando no interior da empresa, com as "oportunidades" a emergirem. Ele nos relata que seu objetivo é fazer um teste para mudar de função - o Programa de Recrutamento Interno (PRI) -, ter um trabaIho melhor e ganhar mais.

[...] antigamente a gente não tinha, assim, muita oportunidade de crescer dentro da empresa, a gente trabalhava, a gente suava, a gente dava a nossa meta, mas a gente num era bem reconhecido pelo trabalho..., mas hoje em dia lá dentro da empresa a gente...é a gente tem... é... chama de PRI, é uma avaliação que a empresa faz. (SAM LEHRER).

No caso do operário em destaque, a promoção no emprego está carregada de uma tripla significação: 1) o reconhecimento de seus esforços em dar o seu melhor para fazer o trabalho fluir de acordo com os interesses da empresa - o que, ao que transparece, para ele, é algo de grande importância (e marca o sentimento do espírito do operário perfeito, cunhado por Taylor); 2) A possibilidade de aumentar seu salário e, dessa forma, poder sanar as múltiplas necessidades que enfrenta no cotidiano e, 3) Inserir-se numa função cujo esforço seja inferior ao que ele vem realizando, atualmente.

Assim, como podemos notar, no âmbito da Casa de Costura o conjunto dos setores existentes, apesar de realizarem atividades específicas, apresentam similaridades em alguns aspectos que marcam suas condições e relações de trabalho. Além disso, estão bastante interligados.

Num diálogo travado com uma trabalhadora da indústria responsável pela coordenação de algumas PUP (Zuzu Angel) - achamos 


\section{temporollis}

interessante a expressão que, por vezes, utilizou para caracterizar a dinâmica de trabalho no espaço fabril-têxtil. Dizia ela: "É mágico!" remetendo-se ao fato de estar tudo muito articulado, concatenado e obedecendo a uma lógica de bastante precisão. Nesse sentido, ao percorrer todas as etapas de produção, o tecido simples poderia ser modificado e, rapidamente, se tornar uma bela peça de roupa a ser comercializada nas lojas. Mas, na realidade, toda mágica se assenta em um truque e, no âmbito da Casa de Costura - assim como de quaisquer outros segmentos industriais - não é diferente. A transformação da matéria prima só é possível com a intensa exploração do trabalho de todos que ali se encontram. Obviamente, o truque precisa estar escamoteado e, por isso mesmo, a exploração do trabalho, a carta na manga do capitalista, acaba sendo "invisibilizada", fazendo com que a produção ganhe essa dimensão mágica.

Desmascarar a farsa significaria surpreender-se com as possibilidades que dispomos de atender as necessidades sociais; significaria reconhecer, como bem demonstrou Vinícius de Moraes com seu "Operário em construção", que tudo ali e ao redor de todos é fruto dos esforços realizados pelo empenho do trabalho de cada um e de todos. Significaria, enfim, descobrir que antes de ser mercadoria, valor de troca, o trabalho é valor de uso, é necessidade humana.

O fio condutor a tecer os nexos da fala de Zuzu Angel tem como centro o elemento tempo. Não apenas por algumas palavras-chave mencionadas repetidas vezes, mas pela própria lógica que perpassa todo o seu depoimento. De um modo ou de outro, todas as ações são guiadas na tentativa de conformar mais produção num reduzido espaço temporal.

Há, inclusive, um ambiente específico para a capacitação dos profissionais, conhecido por "escolinha". Trata-se de uma forma de habilitar as trabalhadoras que estão ingressando na indústria, para que elas se adaptem tanto ao padrão de qualidade quanto ao ritmo exigidos. Contraditoriamente, para algumas operárias, este também passa a ser visto como um mecanismo favorecedor de oportunidades para as pessoas sem experiência, interessadas em trabalhar na fábrica. Fazendo inferência a esta situação, Ida afirma:

[...] hoje em dia tem mais oportunidade pra quem não tem... assim, num conhece nada de costura, mas eles dão oportunidade porque lá dentro tem uma escolinha, que eles vão [...] aprendendo lá mesmo. (IDA JACOBOWSKI). 


\section{tempordis}

O discurso da entrevistada é motivado pela própria trajetória percorrida por ela para alcançar o objetivo de ser admitida para trabalhar na empresa. Ora, quando ela entrou na fábrica ainda não havia esta escolinha e, para fazer o teste de aptidão necessário, necessitou pagar um curso de costura para adquirir alguns conhecimentos básicos na confecção das peças de roupas. E, ainda assim, ela só conseguiu ser aprovada no segundo teste realizado. Por isso, para Ida Jacobowski, há um progresso nessa realidade. Contudo, esse propalado "progresso" nos aparece mais como uma exigência do que como uma iniciativa livre e deliberada da parte dos sujeitos responsáveis por sua idealização.

Assim, atualmente, a inserção na escolinha dá-se nos dois dos três primeiros meses de trabalho, que compreendem o período de experiência. No terceiro mês, elas são transferidas para a própria indústria, onde precisam pôr em prática o que aprenderam. Durante este último mês estarão sendo avaliadas e, nesse sentido, podem ou não continuar fazendo parte do corpo de trabalhadores. Assim como os demais, elas também precisam incorporar o "perfil da empresa" e demonstrar isto na quantidade de peças produzidas.

Interessante notar, nesse sentido, a reflexão de Luiza Brancaccio. Para ela, a escolinha não se limita ao período de três meses, mas materializa-se na própria dinâmica da realidade, que vai impondo aos trabalhadores outras aprendizagens, o entendimento de manuseamento de outras máquinas, etc. Atentemos para seu depoimento:

[...] a escolinha é o cotidiano. Você precisar, num consegue, chega alguém lá, lhe ensina e você acaba aprendendo. Porque nem todas remessas você trabalha com aquela máquina, tem remessa que trabalha só com uma, tem remessa que trabalha só com a outra... Aí vai aprendendo, quando alguém falta... aí a gente tem que dá conta daquele serviço que a outra tava fazendo. (LUIZA BRANCACCIO).

No que tange especificamente ao processo de adaptação propiciado pela escolinha, chamou-nos atenção quando, em seu relato, Zuzu Angel afirmou serem raros os casos de demissão. Segundo ela, isto só ocorre "quando não tem jeito mesmo". Mas esta não foi a realidade a nós exposta por todas as operárias entrevistadas, que afirmaram serem constantes tanto as demissões, quanto as admissões. Acreditamos que, por estar em uma situação "mais favorável" dentro 


\section{temporalis}

da empresa, Zuzu Angel não quis chamar atenção para aspectos da realidade que se mostram, em alguma medida, problemáticos.

Ainda no que se refere a este aspecto, não podemos deixar passar uma informação despercebida: a vivência na escolinha não se restringe apenas aos trabalhadores que se propõem a ocupar a função de costureiros. Também ingressam nela os supervisores das PUP. Estes últimos passam pelo experimento nesse espaço para poder ter noção dos verdadeiros limites, das estratégias e do melhor modus operandi da costura e, consequentemente, cobrar os trabalhadores com mais propriedade. Em resumo: eles preveem, a partir da própria experiência adquirida no espaço, o nível de produtividade que a capacidade humana pode atingir e pautam suas exigências para com os operários a partir disso.

$\mathrm{Na}$ Casa de Costura tempo é dinheiro. Para conseguir potencializar a produção, o espaço industrial é constantemente modificado. Prova disso está na reconfiguração do conhecido sistema de controle da produção de mercadorias, típico do toyotismo. ${ }^{7}$ Tomado em comparação com o semáforo, a depender da cor que estivesse acesa, o trabalhador saberia se poderia continuar no ritmo de produção ou ainda acelerá-lo/diminuí-lo. Ao indagar Zuzu Angel sobre a existência de tais luzes na fábrica, ela afirma tratar-se de uma forma de expor as necessidades da PUP para otimizar o tempo. Nesse sentido, cada luz expressaria uma requisição específica e um funcionário deveria estar encarregado de observar a dinâmica e ir até a PUP supri-la, sem necessitar que a supervisora ou até mesmo uma das costureiras precisasse se ausentar de seu posto de trabalho em busca dos materiais. De acordo com ela, a luz verde indica a necessidade de reposição (agulhas, linhas, etc.), a amarela está relacionada à remessa (retirar os produtos já fabricados) e a vermelha a viés.

Realmente, tomando-se como premissa o fato de que a produção gerada no interior da fábrica, por si só, não é capaz de atender toda a demanda existente, posto que a mesma necessita externalizar uma parte da produção para terceirizadas e facções, não faria sentido estabelecer um mecanismo para controlar a produção, como pretenderia o "semáforo". Mas, diante de um quadro de tantas mutações,

7 Esse modelo se caracteriza, entre outras coisas, por embasar-se em uma produção heterogênea, diversificada, flexível, bastante vinculada à demanda, bem como pelo trabalho em equipe, estrutura horizontal, dentre outros. 


\section{tempordilis}

também permanecíamos com a ideia de que a utilização do sistema de cores teria sido uma adaptação em relação ao sistema originalmente implantado. Para sanar nossa dúvida, retornamos as nossas entrevistadas e, realmente, percebemos que, em períodos anteriores, as referidas luzes cumpriam o papel de controlar o processo produtivo. De acordo com Rosey Safran, nos anos 1990, esse mecanismo das cores existia para mediar à intensidade da fabricação de produtos, mas não era utilizado para reposição de materiais, como ocorre hoje. Naquele período, quando as costureiras necessitavam de agulhas, viés ou qualquer outro utensílio, estabeleciam contato com a supervisora de produção que, por sua vez, se encarregava de atender a necessidade.

Antes de prosseguir, precisamos fazer uma ponderação sobre a disseminação da terceirização no âmbito da produção têxtil, posto que, hoje, ao que parece, ela está sendo utilizada para amedrontar os trabalhadores desse ramo, tornando-os obedientes e atentos ao perfil de operário que a empresa prioriza. Em nossa entrevista com Sam Lehrer, o operário nos relatava uma suposta imposição que estariam fazendo à empresa, para que a mesma contratasse serviços terceirizados, o que acarretaria, como corolário, na demissão de alguns funcionários tornados supérfluos. Vejamos suas palavras:

[...] porque tem esse negócio que aconteceu duma terceirizada, que tá acontecendo aí, que querem que a empresa contrate, de fora pra dentro, aí tão vendo aí como é que vai ficar essa situação. Porque caso aconteça isso aí pode ser que haja corte lá dentro, desse negócio, né? (SAM LEHRER).

Certamente, Sam se refere à expansão do Pró-Sertão ${ }^{8}$. Mas como Zuzu Angel bem elencou, a atual produção realizada na indús-

8 O Pró-Sertão é um programa desenvolvido a partir de uma parceria entre o Governo do Estado do Rio Grande do Norte, a Federação das Indústrias do Rio Grande do Norte (FIERN) e o Serviço Brasileiro de Apoio à micro e pequenas Empresas (Sebrae) que tem como objetivo incentivar a instalação de facções têxteis em algumas regiões do interior do Estado, com o propósito de produzirem peças de roupas requisitadas por grandes empresas da área, a exemplo da Guararapes e Hering. O discurso dos defensores do programa pauta-se, fundamentalmente, no potencial para criação de empregos e fontes de renda, bem como no favorecimento do desenvolvimento industrial da região, senão, vejamos: "A indústria Guararapes se prepara para fixar 300 pequenas facções têxteis, e a Hering, outra empresa do setor, pretende instalar 60 unidades fabris no RN. A previsão inicial é de que o PróSertão consiga gerar aproximadamente 20 mil empregos diretos, produzindo 150 mil peças por dia". (IDEMA, 2013). 


\section{temporollis}

tria não é capaz de suprir a demanda existente. Ao mesmo tempo, ela também nos relata que não é possível depender apenas dos itens oriundos das facções e fabriquetas terceirizadas, posto que a qualidade dos produtos delas oriundos é inferior se comparado com aquele produzido no interior da Casa de Costura. Mas, como desconhece esses fatos, Sam se preocupa em fazer um bom trabalho, para ser reconhecido e "crescer" dentro da empresa. Por certo, esta deve ser a forma que ele considera apropriada para não perder seu cargo para um terceirizado.

Outro trecho da entrevista que nos despertou interesse refere-se ao que Zuzu Angel denominou de "cronoanálise". Segundo ela, o estudo dos tempos e movimentos. E isto nos pareceu interessante por demonstrar uma ruptura com a forma de cálculo no tempo ao longo dos períodos. Nos anos 2000, a entrevistada Annie Rosen afirmava que o cálculo do tempo para as metas estabelecidas e, consequentemente, para a confecção de um produto, baseava-se na própria destreza das costureiras. Vejamos como ela nos relata esta situação:

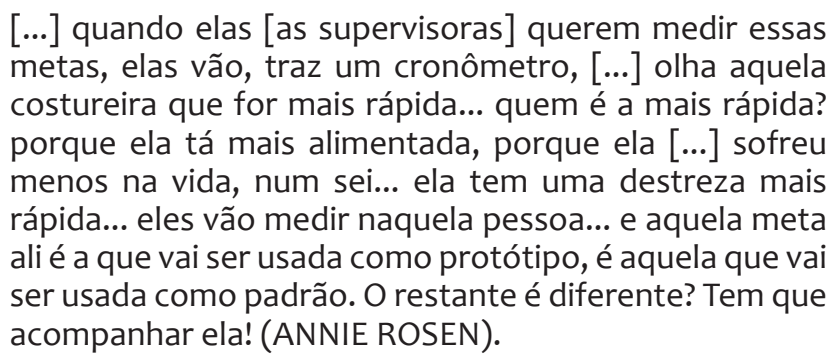

Atualmente, o cronômetro Taylorista persiste, mas este cálculo é extraído de um relatório produzido pelo setor de engenharia da produção, que verifica o menor tempo possível para realizar cada operação. Dessa forma, as trabalhadoras - humanas e, portanto, diversas em sua destreza e habilidade - precisam se adaptar ao tempo das máquinas - inanimadas e uniformes! Pequenas alterações podem ocorrer no que tange ao tempo, a depender da realidade de cada produto fabricado, já que tipos de tecido e costura apresentam graus diversos de dificuldade; alguns podem gerar atrasos. Quando isto ocorre, o engenheiro é novamente acionado e, se ele realmente constatar esta necessidade, o tempo é alterado.

Inclusive, ainda no que tange às questões relacionadas ao tempo, cabe mencionar outros mecanismos ressaltados pela nossa entrevistada: em primeiro lugar, é salutar registrar que, de acordo com os 


\section{tempordilis}

cálculos estipulados, uma mesma costureira pode se tornar responsável por duas operações no processo de produção de uma mesma peça, como casear e adicionar os botões, por exemplo. Ressaltamos que não se trata, aqui, de ter o domínio das outras atividades exigidas, mas, sim, de realizá-las simultaneamente, como tarefa obrigatória. Em ambos os casos, trata-se de mecanismos de incentivo à polivalência das trabalhadoras e, portanto, da exponenciação da intensidade do trabalho. Além disso, a própria lógica de organização das máquinas no interior da indústria pode ser modificada, sempre com vistas a reduzir o máximo possível o tempo necessário. Já há no chão da fábrica, as indicações, em marcas, para tais mudanças, que variam sempre a segundo a demanda existente.

Todo esse processo de fabricação tem como norte uma ficha técnica emitida pelos setores responsáveis por "pensar" o desenvolvimento das peças. Tal ficha fica disponível em cada PUP para orientar o trabalho. Notamos, desta forma, uma nítida separação entre o trabalho intelectual e manual, entre aquelas pessoas que, utilizando de aparatos técnico-científicos serão responsáveis por pensar o produto e aquelas que irão se ocupar de sua produção direta.

Ademais, o quesito "tempo" é, para a Casa de Costura, de extrema relevância, posto que a moda se inscreve num contexto marcado por sucessivas mudanças e a indústria precisa estar antenada com isso. Em resumo, são as requisições do mercado que dão a tônica no processo de produção das peças. Tanto é assim que, na contemporaneidade, prioriza-se a chamada "produção puxada" e não a "produção empurrada". Neste último modo, a fabricação era feita indiscriminadamente e baseada em alguns modelos-chave. Por exemplo, no âmbito da Casa de Costura, o produto central era a camisa polo nas cores preto e branco - assim como o produto das fábricas fordistas era o modelo "T" de automóvel, na cor preta, como rememora Gounet (1999). Nesse sentido, apenas depois de produzidas as camisas é que se buscava saída para elas no mercado. Hoje, com a produção puxada, é preciso ampliar a variedade das peças para atender ao público, além de "regrar" a produção de acordo com a solicitação das lojas.

Relatando-nos o direcionamento de uma reunião recente com um dos diretores da empresa, Zuzu Angel revelou o lema que, atualmente, rege a fábrica, qual seja, "moda com qualidade a preço acessível". Mas, como se pode pensar em qualidade num contexto em que está instalada aquilo que Antunes (2013) qualifica como tendência a 


\section{temporollis}

redução decrescente da taxa de valor de uso dos produtos? Ou seja, como podemos pensar na existência de uma qualidade que convive com a progressiva diminuição do tempo de vida útil das peças, com vistas a possibilitar uma renovação cada vez mais rápida da produção de mercadorias para garantir a obtenção das taxas de lucro? Isso não faz sentido e, de fato, Jacob Klein nos auxilia a desmentir a assertiva consoante sua vivência na produção de malhas. Vejamos o que ele nos relata:

[...] um dia o engenheiro falou pra mim, que é supervisor lá: a tendência da [Casa de Costura] vai ser você vê a lua do outro lado [da malha], porque eles tão afinando pra ganhar mais. (JACOB KLEIN).

Ou seja, estamos diante de mais uma estratégia do capital com vistas a fazer o seu ciclo produtivo reproduzir-se mais rápido. Ora, se a malha é mais fina, consequentemente, o produto terá uma durabilidade menor e, na mesma linha de raciocínio, podemos depreender que as pessoas necessitarão comprar novas peças de roupa em menor tempo, acelerando o consumo. E, como conseguimos observar na fala acima transcrita, trata-se de um movimento calculado, pensado por setores específicos (engenharia). A intencionalidade é clara: reduzir os gastos na confecção dos produtos, diminuindo a qualidade dos tecidos utilizados, com vistas a fazer crescer cada vez mais o lucro do capitalista.

No que se refere às formas encontradas para aumento da lucratividade com as malhas, podemos citar também a disseminação dos produtos produzidos com a malha flamê. Trata-se de um tipo de tecido construído com um fio defeituoso. Se, noutros tempos, era considerado inadequado para a produção das peças de roupas, atualmente ele não é dispensado e chega ao mercado, inclusive como tendência de moda. Assim, o que outrora poderia ser inutilizável, transforma-se na possibilidade de aumentar as taxas de mais-valia.

No caso da Casa de Costura, a dinamicidade da moda cumpre o papel de alavancar e permitir a realização do processo produtivo no ritmo almejado pelo capital. Estamos nos referindo à realidade na qual a necessidade (vestir-se) fica subjugada, ao passo em que ganha relevo os modelos, as cores, os cortes e combinações que estão "em alta", fruto das efêmeras tendências e modinhas que se alastram mundo afora. 
Desse modo, como podemos observar, há algo que unifica todos os setores da produção na indústria Casa de Costura: as formas de precarização da força de trabalho, a exigência pelo atendimento de metas de produtividade e por níveis de qualidade nos produtos, a captura da subjetividade do trabalho e, em síntese, a conformação de um padrão de condições e relações de trabalho cujas desvantagens são evidentes para os trabalhadores.

Todas estas informações condensam a nossa tentativa de derrubar os muros da fábrica, ou seja, de adentrar a empresa capitalista, para conhecer aqueles aspectos que, só quem vive seu cotidiano e participa ativamente de sua (re)produção dinâmica, sente na pele: as trabalhadoras e trabalhadores que tecem suas vidas prostrados defronte máquinas de costura, realizando movimentos repetitivos e exaustivos em meio ao calor, as pressões das metas de produtividade levando uma vida estranhada, sem sentido, pois marcada pela precarização estrutural do ser que trabalha.

\section{Considerações Finais: para arrebentar os fios...}

A expressão "o fio da meada"9 está hipotecada ao advento da revolução industrial na Inglaterra, iniciada por vota da primeira metade do século XVIII. Nesse período, destacava-se a produção na indústria têxtil, e os trabalhadores tinham uma função direta na confecção dos tecidos: colocar a ponta do fio na máquina, no momento certo, para que ela pudesse, assim, produzi-los. Contudo, não raras vezes, esses trabalhadores não o conseguiam fazer, perdendo o fio da meada. No nosso trabalho, recuperar essa expressão faz sentido, de imediato, porque nos permite visualizar o trabalho rotineiro, repetitivo, cansativo, exaustivo...

Em tempos de flexibilização e do desenvolvimento de novas modalidades de precarização do trabalho no universo das compósitas relações de trabalho (SILVA, 2015), o fio da meada nos parece estar associado a um ser que se encontra emaranhado e dominado por esse barbante. Expressa, também, a correria, a instabilidade e a insegurança cotidiana que os homens e mulheres vivenciam para garantir sua subsistência, tentando sobreviver agarrando-se ao fio, por vezes escorregadio, o último fio de esperança. Nessas eras, perder o fio da

9 MANUAL DE IDENTIDADE, 2012. 
meada, significa, metaforicamente, perder a própria vida.

Foi isso que detectamos ao percorrer a indústria têxtil Casa de Costura para entender quais setores existem e como se expressam as atividades dos trabalhadores em cada um deles, na realidade hodierna. Ao passo que procuramos "adentrar" no espaço fabril-têxtil, desenvolvemos esforços a fim de analisar as tendências a envolver o mundo do trabalho no que diz respeito ao processo de precarização do trabalho que acomete os trabalhadores mediante as exigências de metas de produtividade; a inserção dos operários nas ocupações sem o preparo necessário; o incentivo à polivalência ou, numa palavra, a conformação de relações de trabalho assentadas na flexibilização. Ao mesmo tempo, também procuramos evidenciar o conjunto das estratégias acionadas pelo capital em meio à tendência regressiva da taxa de lucros, aos dinamismos espraiados pelo mercado mundial e às demandas por alta produtividade. Em linhas gerais, podemos ter a compreensão das alterações processadas no âmbito da indústria estudada ao mesmo tempo em que observamos como mecanismos antigos persistem no desenvolvimento das atividades, conformando um arranjo particular na organização e gestão da força de trabalho.

Esperamos, assim, que as análises e críticas desenvolvidas ao longo destas páginas possam contribuir, de alguma forma, para desemaranhar todos os sujeitos que vivem as agruras da precarização do trabalho, especialmente os do ramo têxtil. E, sem querer pretender demais, mas também sem perder a utopia tão necessária para alimentar nossos sonhos (ou, como diria Gramsci, aliando o pessimismo da razão ao otimismo da vontade), esperamos contribuir também para ajudar os trabalhadores e trabalhadoras a se desviarem, permanentemente, do fio da meada, fio este que os acorrentam a uma vida sem sentido. Os trabalhadores precisam se agarrar e mover o fio da história que os conduzirá ao reino da liberdade, momento no qual, como apregoou Marx, o livre desenvolvimento de um, será condição para o livre desenvolvimento de todos. Nesse momento, então, encontrar o fio significará tecer outras teias, outra realidade...

\section{REFERÊNCIAS}

ALVES, Giovani. O novo (e precário) mundo do trabalho: reestrutu- 
ração produtiva e crise do sindicalismo. São Paulo: Boitempo, 2005. (Coleção Mundo do Trabalho).

- Trabalho e neodesenvolvimentismo: choque de capitalismo e nova degradação do trabalho no Brasil. Bauru: Canal 6, 2014.

ANTUNES, Ricardo. Os sentidos do trabalho: ensaio sobre a afirmação e a negação do trabalho. 10.ed. São Paulo: Boitempo, 2013. (Coleção Mundo do Trabalho).

CHESNAIS, François. A mundialização do capital. Tradução Silvana Finzi Foá. São Paulo: Xamã, 1996.

FEDERAÇÃO DAS INDÚSTRIAS DO ESTADO DO RIO GRANDE DO NORTE. Guia industrial. [2016]. Disponível em: <http://guiaindustrial. fiern.org.br/cadusuario.php>. Acesso em: 17 ago. 2016.

GONZÁLEZ, Ana Izabel Á. As origens e a comemoração do dia internacional das mulheres. São Paulo: Expressão Popular, 2010.

GOUNET, Thomas. Fordismo e toyotismo na civilização do automóvel. São Paulo: Boitempo, 1999.

HARVEY, David. A condição pós-moderna. São Paulo: Loyola, 1992.

INSTITUTO DE DESENVOLVIMENTO SUSTENTÁVEL E MEIO AMBIENTE. Pró-Sertão vai fixar 360 confecções no interior do Estado. 28 nov. 2013. Disponível em: <http://www.idema.rn.gov.br/Conteudo. asp?TRAN=ITEM\&TARG=14552\&ACT=null\&PAGE=null\&PARM=null\&LBL=Projetos > Acesso em: 23 dez. 2015.

MANUAL DE IDENTIDADE. Fio da meada comunicação. [2012]. Disponível em: <http://fca.pucminas.br/verbo/wp-content/uploads/2012/09/ Agencia-Fio-da-Meada-Manual-de-Identidade-.pdf $>$. Acesso em: 8 maio 2014. 


\section{temporollis}

MARX, Kal. O capital: crítica da economia política. Tradução de Reginaldo Sant'Anna. 13. ed. Rio de janeiro: Bertrand Brasil, 1989. (Livro 1, Volume 1).

MÉSZÁROS, István. Para além do capital: rumo a uma teoria da transição. Tradução de Paulo Cezar Castanheira e Sérgio Lessa. São Paulo: Boitempo, 2009.

PINTO, Geraldo Augusto. A organização do trabalho no século XX: taylorismo, fordismo e toyotismo. São Paulo: Expressão Popular, 2010.

SILVA, Hiago Trindade da Lira. No fio da meada: Um estudo acerca da precarização do trabalho na indústria têxtil. 2015. 268 f. Dissertação (Mestrado em Serviço Social)- Universidade Federal do Rio Grande do Norte, Natal, 2015.

; GUERRA, Eliane Costa. Sobre amarras e grilhões: análise dos instrumentos de regulação do trabalho no âmbito da indústria têxtil "Casa de Costura". Revista Universidade e Sociedade, Brasília-DF, n. 59, jan./jul. 2017. No prelo. 